\title{
Visual Acuity of Four-Wheeled Public Transport Drivers in Jatinangor
}

\author{
Feranika, ${ }^{1}$ Reni Farenia, ${ }^{2}$ Nina Ratnaningsih ${ }^{3}$ \\ ${ }^{1}$ Faculty of Medicine Universitas Padjadjaran Bandung, Indonesia, ${ }^{2}$ Department of Biomedical \\ Sciences Faculty of Medicine Universitas Padjadjaran Bandung, Indonesia, ${ }^{3}$ Department of \\ Ophthalmology Faculty of Medicine Universitas Padjadjaran/Cicendo Eye Hospital Bandung, \\ Indonesia
}

\begin{abstract}
Background: The number of motor vehicles usage is increasing every year, along with the increasing prevalence of motor vehicle accidents, and mortality due to traffic accidents in 2010 . The driver's visual impairment is one factor that affects this phenomenon. In Indonesia there are regulations regarding the minimum requirements for visual acuity in order to get a driving license. However, data of driver's visual acuity have not been obtained yet. This study aimed to assess the public transport (angkot) driver's visual acuity. Thus, the regulation and evaluation of the minimum requirements for a driver's visual acuity can be applied optimally.

Methods: This study used the categorical descriptive method with cross sectional design to assess visual acuity for four-wheeled motor vehicle (angkot) drivers in Jatinangor using RAAB E chart and pinhole. The variable that was described in this study was the visual acuity of 4 -wheeled motor vehicle drivers in Jatinangor.

Results:Results showed $86.5 \%$ of drivers fulfilled the minimum requirements of visual acuity for driving. Meanwhile, the rest did not fulfill the minimum requirements of visual acuity for driving.

Conclusions: Most of the public transport drivers have already fulfilled the minimum requirement of visual acuity for driving. However the minimum requirement of visual acuity for drivers has not been implemented optimally since there were drivers who have not performed an eye examination when taking and extending their driving license.
\end{abstract}

Keywords: Drivers, visual acuity, visual impairment

\section{Introduction}

The number of motor vehicle usage in Indonesia each year continues to rise followed by the increasing prevalence of traffic accidents in Indonesia that reached 27.2\% in year 2008. ${ }^{1}$ One of the influential factors in this phenomenon was the driver's visual acuity which is not suitable for driving.

The term's application of visual acuity of the driver was an appropriate measure to resolve traffic problems caused by the condition of the driver's eye health. This was reaffirmed by the Chief of Police of the Republic of Indonesia, and stated in terms of obtaining a driver's license, number 9 in section 4 in 2012, which mentioned that health requirements are needed to get a driver's license including physical and spiritual health. As for physical health, this meant including physical health or stature, hearing and vision. Driver's visual acuity was measured through visual acuity tests, color test, as well as visual fields. ${ }^{2}$

This study examined the visual acuity of four-wheeled public transport drivers in Jatinangor. This study aimed to analyze the visual acuity of four-wheeled public transport drivers as one of the evaluation of the minimum requirement of visual acuity for drivers.

\section{Methods}

This study used the descriptive method with cross sectional design, and was carried out on Monday-Tuesday, 28-29 October 2014 among four-wheeled public transport drivers at the Padjadjaran clinic and shuttle bus station. This study was using primary data by performing

Correspondence: Feranika, Faculty of Medicine, Universitas Padjadjaran, Jalan Raya Bandung-Sumedang Km.21, Jatinangor, Sumedang, Indonesia, Email: feranikafe@gmail.com 
visual acuity examinations directly to drivers after obtaining approval from the concerned respondents, and data from questionnaires filled in by the respondents. The inclusion criteria in this study were the driver of a public transport vehicle for the routes of the terminal Ranca Mulya-Tanjung Sari-Cileunyi. Meanwhile, the exclusion criteria were the driver who had no driving license, with age less than 17 years or over 50 years, and who at the time of the examination was in an impaired consciousness condition and or suffered eyes' inflammation liked red eyes and infection. Samples were obtained by using the consecutive sampling method. The total number of samples that must be met was based on the formula for minimum descriptive categorical sample, enrolled in this study were 97 persons.

The variables included in this study were visual acuity, age, gender, status of the eye examination when the driver's license was taken and extended, the status for the use of glasses and eye complaints. The visual acuity examination was conducted by a staff member of Ophthalmology and an eye specialist from Cicendo Eye Hospital. The driver's visual acuity in this study used the World Health Organization (WHO) categorization, namely normal vision, and impaired vision including mild, moderate, severe, and blindness. Furthermore, the causes of visual impairment will be classified into refraction abnormalities and non-refraction abnormalities.

This study was approved by the Health Research Ethics Committee of Faculty of Medicine, Universitas Padjadjaran. In order to appreciate the aspects of autonomy, the respondents would be provided information about the examination to be performed and were asked to fill out the sheet of informed consent in advance. After the eye examination was performed, the data would be concealed to ensure the privacy of the respondents. Regarding the aspect of beneficence, the respondents would get benefits because they would know their visual acuity conditions, get a prescription for glasses when there was impairment due to refraction disorders and be given the facility to purchase glasses at a low

Table 1 Characteristics of Respondents

\begin{tabular}{lcc}
\hline \multicolumn{1}{c}{ Variables } & Number (n=52) & Percentage (\%) \\
\hline Gender & 52 & 100 \\
Male & 0 & 0 \\
Female & & \\
Age & 28 & 53.8 \\
17-39 years & 24 & 46.2 \\
40-50 years & & \\
Status of eyeglasses & 2 & 3.8 \\
Yes & 50 & 96.2 \\
No & & \\
Eye status examination when driver takes and & & \\
extends the driving license & 37 & 71.2 \\
Yes & 15 & 28.8 \\
No & & \\
Complaints of eye & 16 & 30.7 \\
Yes & 9 & 17.3 \\
Tenderness & 4 & 7.7 \\
Itchy & 2 & 3.8 \\
Blurred away & 1 & 1.9 \\
Watery eyes & 36 & 69.3 \\
No & &
\end{tabular}


Table 2 Visual Acuity of Public Transport Drivers in Jatinangor

\begin{tabular}{lcc}
\hline \multirow{2}{*}{$\begin{array}{l}\text { Categories of Visual Acuity of The Best Eye with } \\
\text { Available Correction (WHO) }\end{array}$} & \multicolumn{2}{c}{ Basic Visual Acuity } \\
\cline { 2 - 3 } Normal & Number (n=52) & Percentage (\%) \\
Mild Visual Impairment & 45 & 86.5 \\
Moderate Visual Impairment & 3 & 5.8 \\
Severe Visual Impairment & 4 & 7.7 \\
Blindness & 0 & 0.0 \\
\hline
\end{tabular}

price from Cicendo Eye Hospital. Regarding the aspect of non-maleficence, visual acuity screening was carried out as best as possible by a standardized person, and respondents also would earn money for their time. Regarding the aspect of justice, each of the respondents would get the same treatment by following the appropriate research procedures.

\section{Results}

This study used primary data obtained by performing direct visual acuity examinations and interviewing respondents with questionnaires regarding their characteristics. Moreover, visual acuity data were obtained from 52 samples.

The majority of the respondents $(86.5 \%)$ had normal visual acuity on the best eye which meant, they met the minimum requirement of visual acuity for driving. The rest had impaired visual acuity including mild and moderate visual impairment (Table 2).

Furthermore, the percentage of normal eyes were $84.6 \%$ for the right eye and $86,5 \%$ for the left eye. The data showed, there were 8 right eyes and 7 left eyes with visual impairment (Table 3).

The results showed 8 drivers experienced visual impairment and after performing correction of the lens by using a pinhole. Moreover, the eyes of 7 drivers increased to normal and the eye of one driver was in a blind condition (Figure 1). Regarding the left eye, all of the visual acuity increased to a normal vision after the correction was performed by using a pinhole.

Most of the respondents (87.5\%) had visual impairment caused by refraction abnormalities such as myopia, combination of myopia and presbyopia and aphakia (Table 4), and the rest were caused by traumatic cataract, which is a non-refractive error abnormality.

\section{Discussion}

The result of this study showed that $100 \%$ of four-wheeled public transport drivers were men, which was similar to a study conducted by Oladehinde et $\mathrm{al}^{3}$ that the drivers of public transport are male. The results of this study showed the majority of public transport drivers were aged less than 40 years, comprising 28 people with a percentage of $53.8 \%$. The data was different from the study conducted by Ayanniyi et al. ${ }^{4}$, where the majority of driversare aged between 40-44 years. People 40 years of age and over need

Table 3 Visual Acuity of Each Driver's Eye

\begin{tabular}{lcc}
\hline \multirow{2}{*}{ Categories of Visual Acuity of Each Eye } & \multicolumn{2}{c}{ Number } \\
\cline { 2 - 3 } & Right Eye (\%) & Left Eye (\%) \\
\hline Normal & $44(84.6)$ & $45(86.5)$ \\
Mild Visual Impairment & $3(5.8)$ & $3(5.8)$ \\
Moderate Visual Impairment & $4(7.7)$ & $1(1.9)$ \\
Severe Visual Impairment & $0(0.0)$ & $2(3.9)$ \\
Blindness & $1(1.9)$ & $1(1.9)$ \\
\hline
\end{tabular}




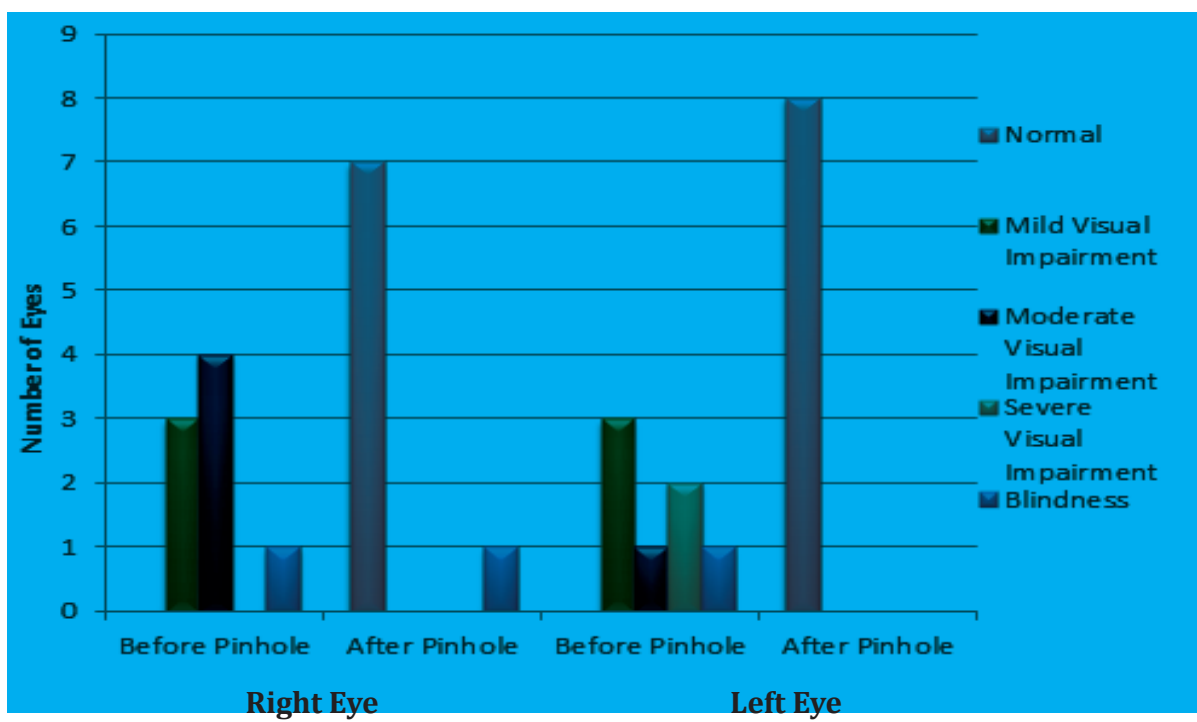

Figure 1 Visual Acuity of Drivers with Visual Impairment in Each Eye

the screening of eye condition because the cases of glaucoma, cataracts and age-related macular degeneration are frequent in this age. ${ }^{4}$ Results of this study found that only 2 people were using eyeglasses. However, further examinations showed there were actually 8 persons who experienced visual impairment of whom 2 persons were using glasses but were not included among the drivers who were having visual impairment.

Furthermore, there were 16 people $(30.7 \%)$ who had eye complaints including blurred vision when see from far distance, tender eyes, itchy eyes, and watery eyes. However, after the examinations, only 8 people had visual impairment and only 4 people among them had eye complaints.

An overview of this study revealed that the application of the minimum requirement regulation of visual acuity for the driver has not yet been implemented optimally. There was still as many as $28.8 \%$ of drivers who did not perform the eye examination when they took and extended their driving license. This is similar to a study conducted in Nigeria by Oladehinde et al. ${ }^{3}$ where the majority of motor vehicle drivers $(83.6 \%)$ never perform eye examinations when making a license.

Moreover, this study showed that there were still $13.5 \%$ of four-wheeled public transport drivers who did not fulfill the minimum requirements of visual acuity for driving. The driver's visual impairment in this study was mostly caused by refraction abnormalities. Refraction abnormalities occurring in this study were myopia, combination of myopia and presbyopia, and aphakia as might be seen from the increase of visual acuity after correction by using a pinhole. According to Resnikoff et al. $^{5}$, the global prevalence of refraction

Table 4 Causes of Visual Impairment of Drivers

\begin{tabular}{lcc}
\hline \multicolumn{1}{c}{ Diagnosis } & Number (n=8) & Percentage (\%) \\
\hline Refractive Errors & & \\
Myopia & 5 & 62.5 \\
Myopia \& Presbyopia Combination & 1 & 12.5 \\
Aphakia & 1 & 12.5 \\
Non-Refractive Errors & & \\
$\quad$ Traumatic Cataract & 1 & 12.5 \\
\hline
\end{tabular}


abnormalities reached $1.1 \%$ at the age of 16-39 years. It was different from studies that included presbyopia in refractive errors while presbyopia, hyperopia and myopia were the most common ocular conditions found among the drivers. The uncorrected refractive error is a known cause of visual impairment and blindness, and can limit ability to drive. ${ }^{6-9}$ Another study by Schellini et al. ${ }^{10}$ also showed the main causes of low vision and blindness are uncorrected refractive errors, cataract, and retinal diseases.

In addition, the impaired vision may also be due to a non-refractive cause, such as by traumatic cataract conditions that occurred in this study. Refractive errors and cataract contributed to over $85 \%$ of presenting visual impairment and over $60 \%$ of WHO-defined visual impairment. ${ }^{11}$

In conclusion, there are still $13.5 \%$ of drivers who do not fulfill the minimum requirement of visual acuity for driving. The minimum requirement regulation of visual acuity for drivers has not been carried out with maximum effort because there were still $28.8 \%$ of drivers who have not taken the eye examination when they take and extend their driving license.

Limitations of this study were the unavailability of studies about the factors affecting the driver's visual impairment. It can be suggested to the relevant institutions, like the Indonesian National Police and the Department of Transportation in Indonesia to enhance implementation of the minimum visual acuity requirements. Moreover, a further study should be conducted to another kind of driver with high risks such as the truck driver.

\section{References}

1. Badan Pusat Statistik. Jumlah kecelakaan, korban mati, luka berat, luka ringan, dan kerugian materi yang diderita tahun 19922012. [2014 February 20]; Available from: www.bps.go.id.

2. Kepolisian Negara Republik Indonesia.
Peraturan kepala kepolisian negara republik indonesia nomor 9 tahun 2012 tentang surat izin mengemudi; 2012.

3. Oladehinde MK, Adeoye AO, Adegbehingbe BO, Onakoya AO. Visual functions of commercial drivers in relation to road accidents in Nigeria. Indian J Occup Environ Med. 2007;11(2):71-5.

4. Ayanniyi AA, Chikwe AC. Eye screening for automobile drivers: the need to make it mandatory eye test among automobile drivers. Sudanese J Public Health. 2012;7(2):41-6.

5. Resnikoff S, Pascolini D, Mariotti SP, Pokharel GP. Global magnitude of visual impairment caused by uncorrected refractive errors in 2004. Bulletin of the World Health Organization; 2008;86(1):63-70.

6. Ayanniyi AA, Folorunso FN, Adepoju FG. Refractive ocular conditions and reasons for spectacles renewal in a resource-limited economy. BioMed Central Ophthalmol. 2010;10(12):1-7.

7. Patel I, West SK. Presbyopia: prevalence, impact, and interventions. Community Eye Health. 2007;20(63):40-1.

8. Ayanniyi AA, Adepoju FG, Ayanniyi RO, Morgan RE. Challenges, attitudes and practices of the spectacle wearers in a resource-limited economy. Middle East Afr J Ophthalmol. 2010;17(1):83-7.

9. Ayanniyi AA, Fadamiro CO. Opinion of the patients on the free eye care intervention in a resource limited economy. Asian J Ophthalmol. 2009;11(2):91-5.

10. Schellini SA, Durkin SR, Hoyama E, Hirai F, Cordeiro R, Casson RJ. et. al. Prevalence and causes of visual impairment in a Brazilian population: the botucatu eye study. BioMed Central Ophthalmol. 2009;9(8):1-9.

11. Onakpoya $\mathrm{OH}$, Adeoye AO, Akinsola FB, Adegbehingbe BO. Prevalence of blindness and visual impairment in Atakunmosa west local government area of Southwestern Nigeria. Tanzan Health Res Bull. 2007;9(2):126-31. 